\title{
Relief and euphoria greet decision on LHC
}

Munich. Particle physicists can celebrate Christmas secure in the knowledge that 20 years of high-level science lie before them. Last week, the council of the European Laboratory for Particle Physics (CERN) approved construction of the Large Hadron Collider (LHC), one of the largest basic science research projects ever undertaken.

The decision was greeted with a mixture of relief and euphoria by CERN staff, whose confidence that the LHC would be built has been deeply shaken over the past six months. As one compromise solution after another was rejected, it seemed that tough conditions demanded by Germany and Britain would never be met. Now, according to an agreement that meets almost all of the German/UK demands, the accelerator will be built in two phases according to a baseline programme that assumes no financial contribution from non-member states.

After the demise last autumn of the Superconducting Super Collider, a competitor to the LHC planned by the United States (see Nature 365, 773; 1993), particle physicists have been pinning their hopes on Europe's proposed LHC

Last June, CERN's 19 member states agreed in principle to build the accelerator, at a total cost of SFr2.6 billion (US $\$ 1.98$ billion), inside an existing tunnel that runs in a $27-\mathrm{km}$ circle beneath the French-Swiss border at Geneva.

The financial package offered by CERN to its member states at that time was SFr500 million more than they would have been able to pay out of their annual contributions. Christopher Llewellyn Smith, CERN's director-general, wanted the shortfall to be made up by contributions from non-member states.
But Germany and the United Kingdom made a series of proposals to reduce costs and ensure that the project could be independent from outside contributions. First, they argued, the cost of the LHC should be pegged to 1995 levels to ensure it remained affordable, and the host countries, Switzerland and France, should pay ten per cent of the total costs - SFr260 million over ten years - in addition to their annual contributions.

The new agreement is based on zero growth in the budget between 1995 and 1997. Thereafter, assuming a 2 per cent inflation rate, member states will be asked to pay only one per cent more a year until 2008. France and Switzerland, however, will increase their subscriptions by two per cent a year over this 10 -year period, adding an estimated SFr123 million.

Llewellyn Smith: to adopt two-phase plan.

Taken on top of their promised host state contribution of SFr121.5 million (SFr57 million from Switzerland, SFr64.5 million from France), this means that they will indeed foot nearly 10 per cent of the total bill on top of their general subscription.

Germany and the United Kingdom also wanted voting rules to be changed so that a request from CERN to raise indexation could be overruled by member countries with a combined contribution to the CERN budget of one-third. (The two countries contribute around 22.5 per cent and 14 per cent respectively to CERN's budget.)

\section{Japan and US explore collaboration}

Tokyo. It will be at least a year before it is clear whether Japan is in a position to contribute to the construction costs of the Large Hadron Collider (LHC), following Europe's failure to reach agreement on the LHC in June (see Nature 370,$165 ; 1994$ ).

In late 1993, Japanese physicists decided to back the LHC when the United States cancelled the Superconducting Super Collider (SSC). Earlier this year they were pushing with the Ministry of Education, Science, and Culture to win a budget for the LHC in the fiscal year 1995 (which begins in April). But the opportunity has now passed.

Hirotaka Sugawara, director general of Japan's National Laboratory for High Energy Physics (KEK), now says that he will do his "very best" to emphasize the importance of the LHC and of Japan contributing to the construction of detectors and "even to construction of the collider itself".

But it will be late August next year before a budget request can be made (for fiscal year 1996) and a decision by the Ministry of Finance would not be made until the end of December.

Meanwhile Martha Krebs, director of the office of energy research (OER) at the US Department of Energy, said last week that she was "very pleased" that CERN has made the decision to go ahead with LHC.

Krebs said that the United States was now taking two steps over its possible participation. First, an interagency group will meet shortly after the new year to develop the US approach to discussions with the European organization. Second, John O'Fallon, head of the OER's highenergy physics division, had already invited the CERN team to visit the United States for talks. David Swinbanks \& Colin Macilwain
Third, Germany and the United Kingdom had asked for harsh reductions in the general CERN budget. The laboratory has now agreed to lose 600 of its 2,900 staff by the year 2005, saving an estimated SFr25 million a year. Combined with other previously agreed savings, this means that a total of SFr 800 million will be trimmed from the general CERN budget by 2008 .

The severity of the German/UK demands caused tension between member states. Some felt that Germany, the highest contributor to CERN, was using its financial muscle to hold the project to ransom. Many of the issues, says Filippo Menzinger, a spokesman for the Italian delegation, could have been dealt with earlier, without tying them to the LHC decision.

In addition to the budget-trimming exercises, the timetable for LHC construction and experiments has been adjusted to spread the costs over a longer period. The collider will now be built in two phases. In the initial phase, up to 2008, the machine will be constructed to run at an energy level of 9.3 $\mathrm{TeV}$, by omitting one-third of the accelerator's planned 1,200 magnets.

Lynn Evans, the director of the LHC, says that this energy is still sufficiently high to answer fundamental questions such as why the Universe is constructed entirely of matter, rather than the predicted mixture of matter and antimatter, and to carry out research on the top quark.

After 2008, the remaining magnets will be installed to allow the LHC to achieve its top energy of $14 \mathrm{TeV}$. Particle physicists will finally be able to seek their holy grail, the Higg's boson, a particle whose purported existence underpins theories of mass.

These plans will be reviewed in 1997. If CERN receives firm offers before the review from countries that have already expressed serious interest - the United States, Japan, Canada, the Russian Federation, India and Israel - it will be possible to build the $14-\mathrm{TeV}$ accelerator by 2005 as originally planned.

"I would estimate the chances of [an accelerated timescale] to be strong," says Llewellyn Smith, who is flying to Washington next month to begin formal negotiations with the United States.

Not surprisingly, officials in both Germany and the United Kingdom have expressed satisfaction with the outcome. The German minister for research, Jürgen Rüttgers, says that the decision gives particle physics a secure future, and with a considerble saving to the budget.

Britain's Office of Science and Technology, which coordinated the UK's role in the final negotations, says that the savings there will be used to support domestic research.

Allson Abbott 